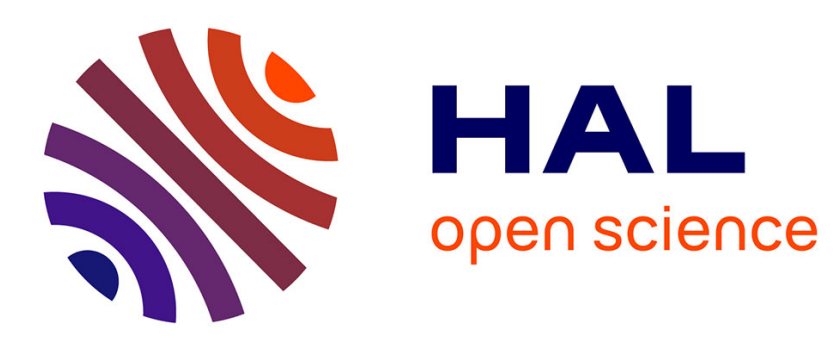

\title{
Denoising NMR time-domain signal by singular-value decomposition accelerated by graphics processing units
}

Pascal Man, Christian Bonhomme, Florence Babonneau

\section{To cite this version:}

Pascal Man, Christian Bonhomme, Florence Babonneau. Denoising NMR time-domain signal by singular-value decomposition accelerated by graphics processing units. Solid State Nuclear Magnetic Resonance, 2014, 61-62, pp.28-34. 10.1016/j.ssnmr.2014.05.001 . hal-01275072

\section{HAL Id: hal-01275072 \\ https://hal.science/hal-01275072}

Submitted on 30 Apr 2020

HAL is a multi-disciplinary open access archive for the deposit and dissemination of scientific research documents, whether they are published or not. The documents may come from teaching and research institutions in France or abroad, or from public or private research centers.
L'archive ouverte pluridisciplinaire HAL, est destinée au dépôt et à la diffusion de documents scientifiques de niveau recherche, publiés ou non, émanant des établissements d'enseignement et de recherche français ou étrangers, des laboratoires publics ou privés. 


\title{
Denoising NMR time-domain signal by singular-value decomposition accelerated by graphics processing units
}

\author{
Pascal P. Man ${ }^{\mathrm{a}, \mathrm{b}, *}$, Christian Bonhomme ${ }^{\mathrm{c}, \mathrm{d}}$, Florence Babonneau ${ }^{\mathrm{c}, \mathrm{d}}$ \\ a Sorbonne Universités, UPMC Univ Paris 06, FR 2482, Institut des matériaux de Paris-Centre, Collège de France, F-75005 Paris, France \\ ${ }^{\mathrm{b}}$ CNRS, FR 2482, Institut des matériaux de Paris-Centre, Collège de France, F-75005 Paris, France \\ ' Sorbonne Universités, UPMC Univ Paris 06, UMR 7574, Chimie de la Matière Condensée de Paris, Collège de France, F-75005 Paris, France \\ d CNRS, UMR 7574, Chimie de la Matière Condensée de Paris, Collège de France, F-75005 Paris, France
}

\begin{abstract}
We present a post-processing method that decreases the NMR spectrum noise without line shape distortion. As a result the signal-to-noise $(\mathrm{S} / \mathrm{N})$ ratio of a spectrum increases. This method is called Cadzow enhancement procedure that is based on the singular-value decomposition of time-domain signal. We also provide software whose execution duration is a few seconds for typical data when it is executed in modern graphic-processing unit. We tested this procedure not only on low sensitive nucleus ${ }^{29} \mathrm{Si}$ in hybrid materials but also on low gyromagnetic ratio, quadrupole nucleus ${ }^{87} \mathrm{Sr}$ in reference sample $\mathrm{Sr}\left(\mathrm{NO}_{3}\right)_{2}$. Improving the spectrum $\mathrm{S} / \mathrm{N}$ ratio facilitates the determination of $\mathrm{T} / \mathrm{Q}$ ratio of hybrid materials. It is also applicable to simulated spectrum, resulting shorter simulation duration for powder averaging. An estimation of the number of singular values needed for denoising is also provided.
\end{abstract}

\section{Introduction}

The accuracy and efficiency of data post-processing and quantification are paramount for NMR applications. In medical applications, reliable estimates of NMR spectral parameters must be deduced from low signal-to-noise $(\mathrm{S} / \mathrm{N})$ ratio spectrum [1]. In solid state NMR, time-domain signal averaging is common practice for improving $\mathrm{S} / \mathrm{N}$ ratio of spectrum, but this increases NMR machine time. We apply the Cadzow enhancement procedure [2] for denoising NMR time-domain signal, resulting spectrum with better $\mathrm{S} / \mathrm{N}$ ratio, which permits us to shorten NMR machine time.

This enhancement procedure is based on the singular-value decomposition (SVD) of an Hankel matrix [3] constructed with the NMR time-domain signal. Theoretical investigations focused on signal enhancement of a sum of sinusoids $[2,4]$. This procedure is already involved in numerous NMR applications [5-12]. Denoising signal becomes a preliminary step before the application of modelfitting methods to extract spectral parameters.

SVD of a large matrix is a computationally-intense operation, which limited its introduction in NMR processing software. Fortunately, modern graphics processing unit (GPU), whose original

\footnotetext{
* Corresponding author at: Sorbonne Universités, UPMC Univ Paris 06, FR 2482 Institut des matériaux de Paris-Centre, Collège de France, F-75005 Paris, France. E-mail address: pm@pascal-man.com (P.P. Man).
}

purpose is to improve graphics acceleration operations in 3D computer games, becomes programmable for general-purpose computation [13-17]. GPU becomes a co-processor of the main central processing unit for massive parallel computation.

In this article, we first describe the Cadzow enhancement procedure for denoising NMR time-domain signal. Then we test our SVD programs $[18,19]$ not only to insensitive nucleus ${ }^{29} \mathrm{Si}$ in hybrid materials, but also to low gyromagnetic ratio, quadrupole nucleus ${ }^{87} \mathrm{Sr}(I=9 / 2,7.02 \%$ natural abundance) $[20]$ in reference sample $\operatorname{Sr}\left(\mathrm{NO}_{3}\right)_{2}$ studied by Larsen and co-workers [21] and Bowers and co-workers [22]. Furthermore, ${ }^{29} \mathrm{Si}$ MAS spectrum with large $S / N$ ratio facilitates the determination of $T / Q$ ratio of hybrid materials from spectrum decomposition. The $\mathrm{Q}$ species describe the connectivity of the silicate network and the $\mathrm{T}$ species are indicative of a silicon atom from a silicate network that is bound to a carbon atom. We also denoise time-domain signals simulated with SIMPSON [23], whose line shapes are asymmetric. Thanks to modern GPU, SVD execution duration has been shorten dramatically, from 80 down to $2 \mathrm{~s}$ for typical solid state NMR data.

\section{Cadzow enhancement procedure}

The enhancement procedure of NMR time-domain signal involves Hankel matrix $[3,24], \mathbf{H}$, in which each descending diagonal from right 
to left is constant:

$H_{i, j}=H_{i-1, j+1}$

First, we fill the first row and the last column of $\mathbf{H}$ with the complex numbers of the time-domain signal $[2,25]$. Fig. 1A shows a simple $4 \times 3$ matrix $\mathbf{H}$ where the time-domain digitised data are the series $[a, b, c, d, e, f]$ coloured in red. The remaining matrix elements are filled according to Eq. (1). Second, $\mathbf{H}$ is decomposed $[1,26]$ as shown in Fig. 1B where the singular-value matrix $\boldsymbol{\Sigma}$ consists of three positive values $\Sigma_{1}, \Sigma_{2}$ and $\Sigma_{3}$. Third, we zero the weakest singular value $\Sigma_{3}$. Fourth, we construct a new $4 \times 3$ matrix with this reduced number of singular value $\left(N_{\mathrm{SVD}}\right)$ matrix as shown Fig. 1C; however, this new matrix is not of Hankel structure. Finally, we restore this matrix to Hankel one by averaging the elements of each descending diagonal from right to left as shown Fig. 1D. The denoised time-domain signal is provided by the first row and the last column of this matrix, which are coloured in red in Fig. 1D. If the corresponding spectrum is still too noisy, we repeat the procedure to the denoised time-domain signal by keeping the number of singular values smaller than or equal to the previous case. Cadzow [2] used Toeplitz matrix [27]

A

$$
\boldsymbol{\Psi}=\begin{array}{|l|l|l|}
\hline \mathrm{a} & \mathrm{b} & \mathrm{c} \\
\hline \mathrm{b} & \mathrm{c} & \mathrm{d} \\
\hline \mathrm{c} & \mathrm{d} & \mathrm{e} \\
\hline \mathrm{d} & \mathrm{e} & \mathrm{f} \\
\hline
\end{array}
$$

B

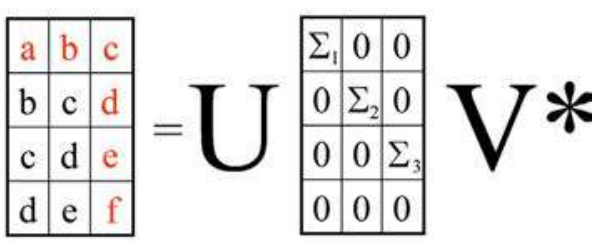

C

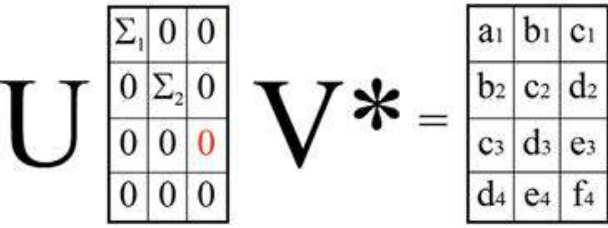

D

\begin{tabular}{|c|c|c|}
\hline a1 & $\frac{b 1+b 2}{2}$ & $\frac{c 1+c 2+c 3}{3}$ \\
\hline$\frac{b 1+b 2}{2}$ & $\frac{c 1+c 2+c 3}{3}$ & $\frac{d 2+d 3+d 4}{3}$ \\
\hline$\frac{c 1+c 2+c 3}{3}$ & $\frac{d 2+d 3+d 4}{3}$ & $\frac{e 3+c 4}{2}$ \\
\hline$\frac{d 2+d 3+d 4}{3}$ & $\frac{e 3+e 4}{2}$ & \\
\hline
\end{tabular}

Fig. 1. Cadzow enhancement procedure: (A) $4 \times 3$ Hankel matrix $\mathbf{H}$ containing the digitised noisy time-domain signal series $[a, b, c, d, e, f]$ in its first row and its last column; (B) decomposition of $\mathbf{H}$ where the three singular values are $\Sigma_{1}, \Sigma_{2}$ and $\Sigma_{3}$; (C) the time-domain signal series is denoised by zeroing the smallest singular value $\Sigma_{3}\left(N_{\mathrm{SVD}}=2\right)$ then a new $4 \times 3$ Hankel matrix is recomposed; (D) the matrix elements resulting from (c) are averaged so that the matrix is of Hankel structure; the denoised time-domain signal series is located in its first row and its last column. (For interpretation of the references to color in this figure legend, the reader is referred to the web version of this article.) instead of Hankel one in his presentation, in which each descending diagonal from left to right is constant.

From a practical point of view, an $m \times n$ Hankel complex matrix represents a free induction decay (FID) whose size is $N=m+n-1$. The number of columns $n$ of $\mathbf{H}$ should be much larger than the optimum number of singular values, because the enhanced signal strongly depends on $n$ and $N$ [1].

As we also want to improve the time-domain signals of quadrupole nuclei [28], which usually have asymmetric line shapes, we proceed in another way as shown the flow chart in Fig. 2. The problem is that the optimum number of singular values cannot be guessed. We first apply the line broadening (LB) processing to decrease the noise [4]. After the decomposition of $\mathbf{H}$, it is simpler to start with the first singular value, which has the

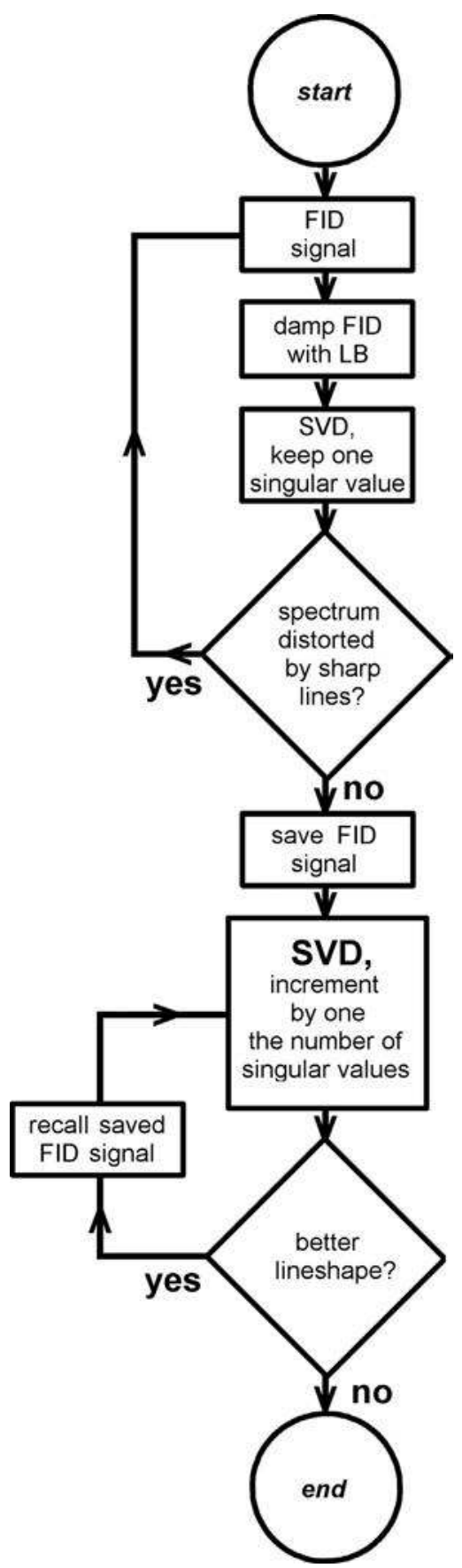

Fig. 2. Flow chart for SVD denoising time-domain signal, free induction decay (FID) for short. 
highest value. If the spectrum resulting from the denoised timedomain signal is not satisfactory, we increase the number of singular values until the line shape is recovered.

\section{Experimental}

NMR experiments for magic-angle spinning (MAS) ${ }^{29} \mathrm{Si}$ in hybrid materials were performed with Bruker Avance III 500 at $99.36 \mathrm{MHz}$ and $4-\mathrm{mm}$ diameter rotor. Those for static ${ }^{87} \mathrm{Sr}$ in $\mathrm{Sr}\left(\mathrm{NO}_{3}\right)_{2}$ were performed with Avance III 850 spectrometer at 36.83 $\mathrm{MHz}$ and 9.5-mm diameter Varian rotor.

Two-pulse phase-modulation-15 (TPPM-15) high-power proton decoupled ${ }^{29} \mathrm{Si}$ MAS data of hybrid materials were recorded with the following parameters: the number of scans (NS) was 40 per experiment, 180 -s recycle delay, $5.72-\mu s \pi / 2$-pulse, $9.44-\mu s$ proton $\pi$-pulse, $10-\mathrm{kHz}$ rotor speed and the number of digital sampling points or TD was 1214 .

TPPM-15 high-power proton decoupled ${ }^{29} \mathrm{Si}$ MAS quadrupole Carr-Purcell-Meiboom-Gill (QCPMG) echo train of hybrid materials were recorded with $\mathrm{NS}=48$ per experiment, 180 -s recycle delay, 50- $\mu$ s pulse ring down, 2-ms FID acquisition, 6.30- $\mu \mathrm{s}$ $\pi / 2$-pulse, 12.70 - $\mu$ s $\pi$-pulse, 9.9 - $\mu$ s proton $\pi$-pulse, $20-\mathrm{kHz}$ spectral width $(\mathrm{SW}), 10-\mathrm{kHz}$ rotor speed, $\mathrm{TD}=1564$ and one FID and 8 echoes recorded.

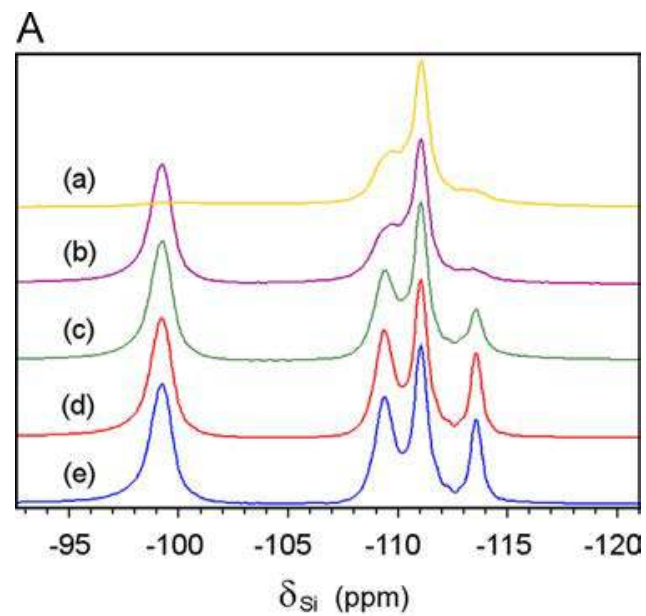

B

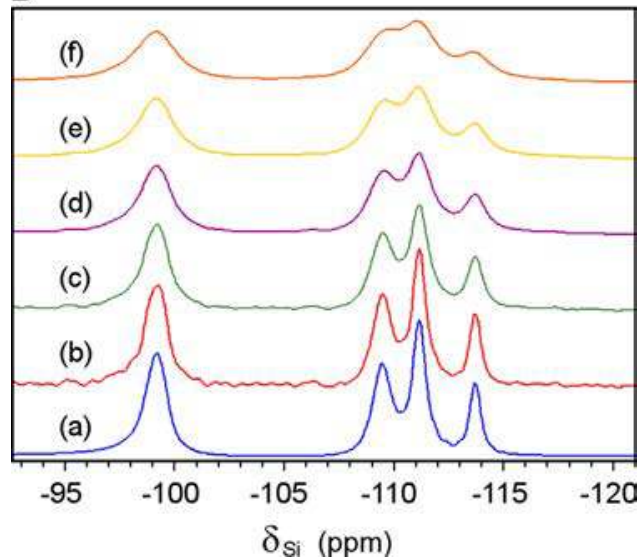

Fig. 3. ${ }^{29} \mathrm{Si}$ MAS spectra of Magadiite: (A) Spectra denoised with the first 1 (a) 2 (b), 3 (c), 4 (d) and 5 (e) singular values. (B) Comparison between SVD denoising and line broadening (LB) denoising: (a) spectrum denoised with the first 4 singular values; (b) non-denoised spectrum; spectra denoised with $L B=20$ (c), 50 (d) 70 (e) and 100 (f) $\mathrm{Hz}$.
Two-pulse, full Hahn echo ${ }^{87} \mathrm{Sr}$ data were recorded with $\mathrm{NS}=3600$ per experiment, 1-s recycle delay, 22- $\mu \mathrm{s}$ liquid $\pi / 2$-pulse with an RF magnetic field $\omega_{\mathrm{RF}} / 2 \pi=11.4 \mathrm{kHz}, 4.4-\mu \mathrm{s}$ solid $\pi / 2$-pulse, 8.8 - $\mu$ s solid $\pi$-pulse, $93.4-\mu$ s delay between the 2 pulses, $\mathrm{SW}=1 \mathrm{MHz}$ and $\mathrm{TD}=1024$.

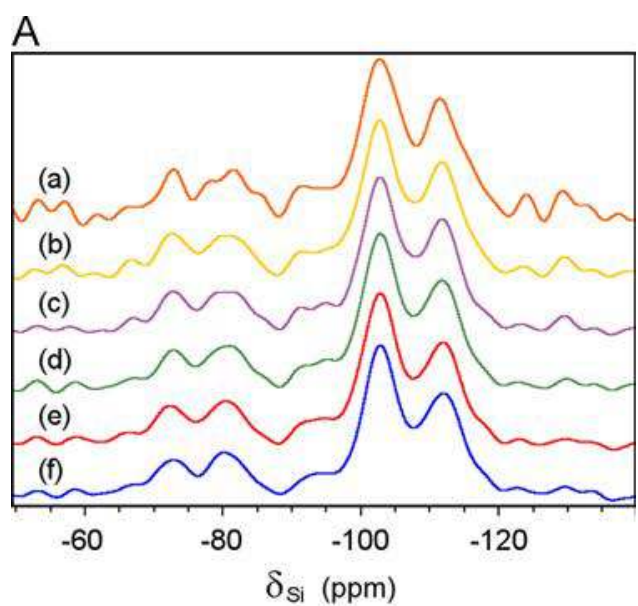

B

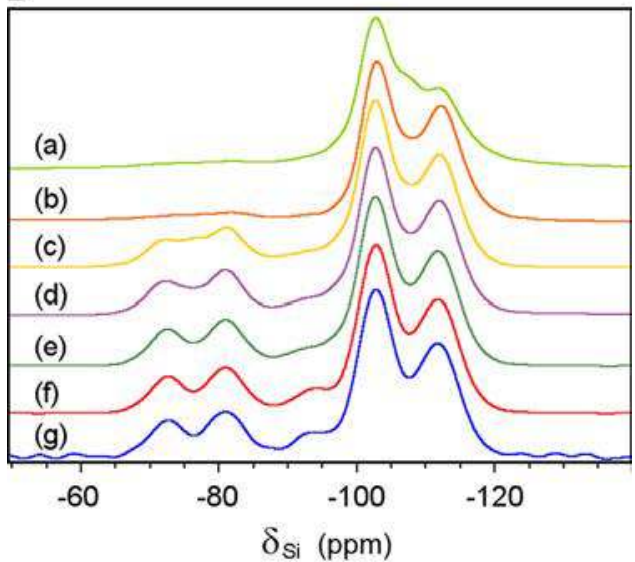

C

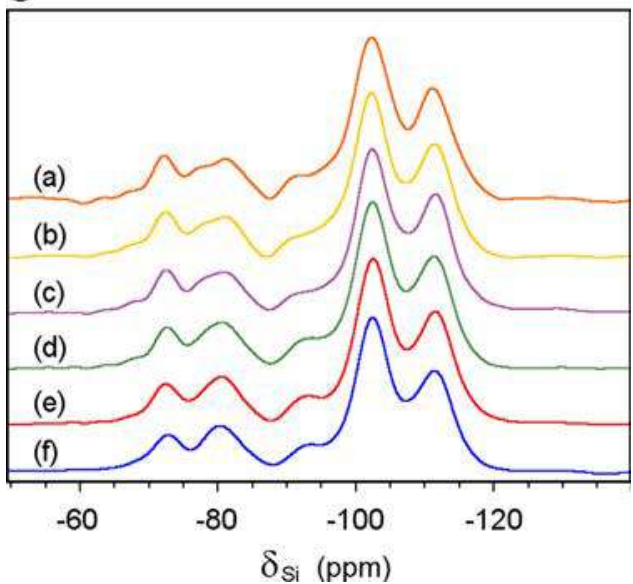

Fig. 4. TPPM-15 high-power proton decoupled ${ }^{29} \mathrm{Si}$ MAS spectra of hybrid materials: (A) Spectra acquired with (a) 40 scans, 2 h of machine time; (b) 80 scans, $4 \mathrm{~h}$; (c) 120 scans, $6 \mathrm{~h}$; (d) 160 scans, $8 \mathrm{~h}$; (e) 200 scans, $10 \mathrm{~h}$; (f) 240 scans, $12 \mathrm{~h}$. (B) Denoised spectra of that acquired with 1200 scans, $60 \mathrm{~h}$ of machine time, where the first 1 (a), 2 (b), 3 (c), 4 (d), 5 (e) and 6 (f) singular values were considered; (g) non-denoised spectrum. (C) Denoised spectra shown in (A) with the first 6 singular values $\left(N_{\mathrm{SVD}}=6\right)$. 
Table 1

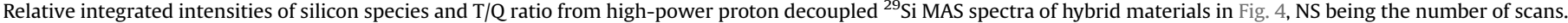

\begin{tabular}{|c|c|c|c|c|c|c|c|c|}
\hline Spectrum & & NS & $\mathrm{T}^{2}(\%)$ & $\mathrm{T}^{3}(\%)$ & $\mathrm{Q}^{2}(\%)$ & $\mathrm{Q}^{3}(\%)$ & $\mathrm{Q}^{4}(\%)$ & $\mathrm{T} / \mathrm{Q}$ \\
\hline \multirow[t]{5}{*}{ Experimental } & B-g & 1200 & 8.0 & 11.6 & 6.6 & 40.0 & 33.9 & 0.24 \\
\hline & A-c & 120 & 7.0 & 12.0 & 6.3 & 41.6 & 33.1 & 0.23 \\
\hline & A-d & 160 & 7.4 & 11.9 & 7.1 & 40.4 & 33.3 & 0.24 \\
\hline & A-e & 200 & 8.8 & 11.2 & 7.9 & 40.1 & 32.1 & 0.25 \\
\hline & A-f & 240 & 9.2 & 11.5 & 6.8 & 38.3 & 34.2 & 0.26 \\
\hline \multirow[t]{5}{*}{ SVD denoised } & B-f & 1200 & 8.3 & 11.5 & 6.9 & 39.3 & 34.0 & 0.25 \\
\hline & $\mathrm{C}-\mathrm{c}$ & 120 & 7.8 & 12.1 & 6.8 & 40.0 & 33.4 & 0.25 \\
\hline & C-d & 160 & 7.5 & 12.8 & 8.7 & 40.0 & 31.0 & 0.25 \\
\hline & C-e & 200 & 8.2 & 12.4 & 8.2 & 39.2 & 32.0 & 0.26 \\
\hline & $C-f$ & 240 & 8.3 & 13.1 & 8.5 & 39.0 & 31.0 & 0.27 \\
\hline
\end{tabular}

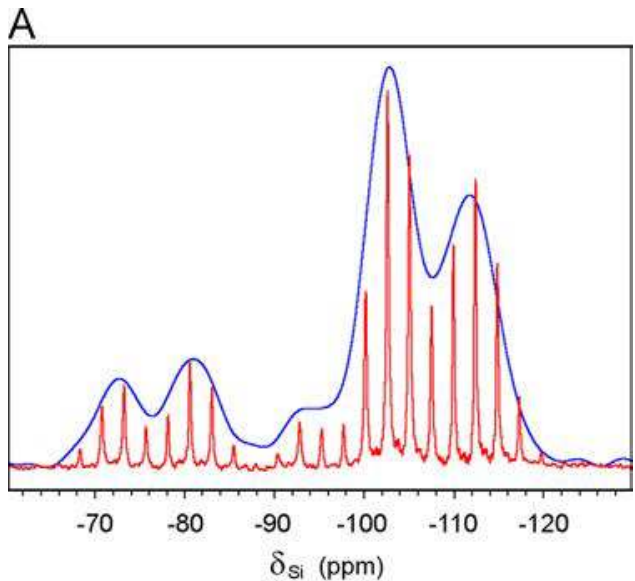

B

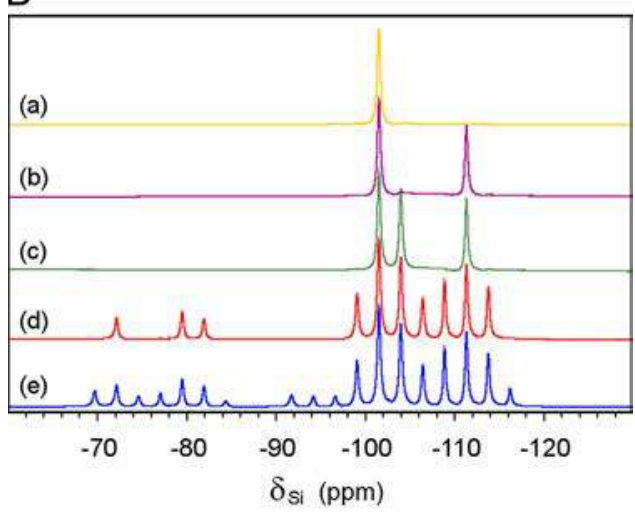

C

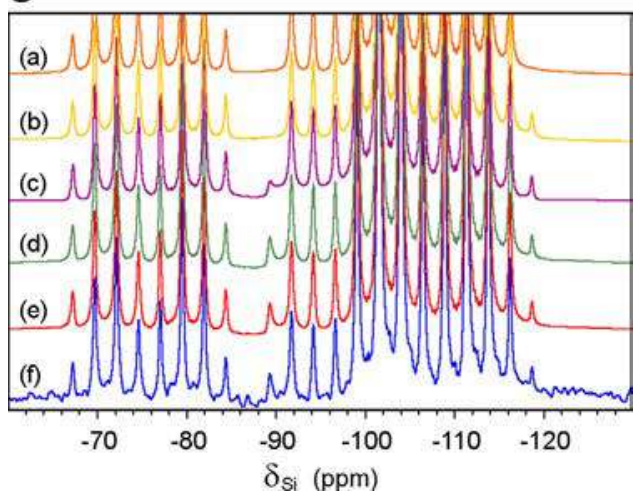

Fig. 5. TPPM-15 high-power proton decoupled ${ }^{29}$ Si MAS QCPMG spikelet spectra of hybrid materials acquired with 1200 scans, $60 \mathrm{~h}$ of machine time, resulting from Fourier transform of the FID and 9 echoes: superposition with Fig. 4B-g (A); spectra denoised with the first 1 (B-a), 2 (B-b), 3 (B-c), 10 (B-d), 20 (B-e), 22 (C-a), 23 (C-b), 24 (C-C), 25 (C-d) and 26 (C-e) singular values; non-denoised spectrum (C-f).

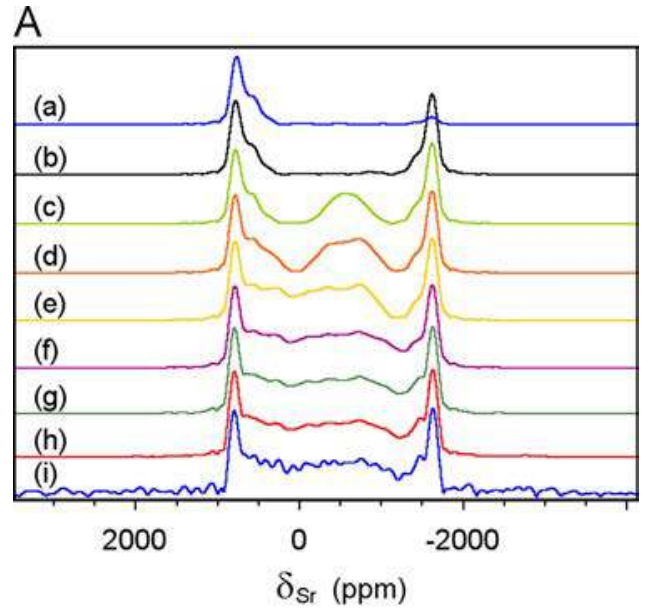

B

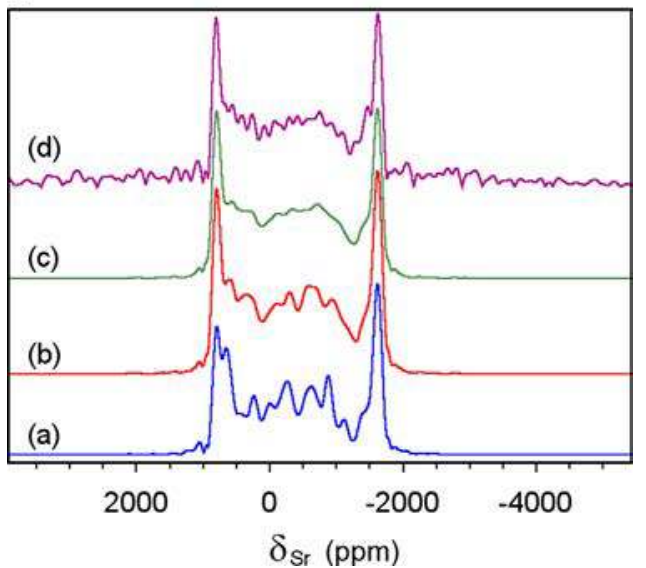

Fig. 6. (A) Denoised ${ }^{87} \mathrm{Sr}$ static spectra of $\mathrm{Sr}\left(\mathrm{NO}_{3}\right)_{2}$ acquired with two-pulse, full Hahn echo sequence and $15 \mathrm{~h}$ of machine time: only the first 1 (a), 2 (b), 3 (c), 4 (d), 5 (e), 6 (f), 7 (g) and 8 (h) singular values are considered; (i) non-denoised spectrum. (B) Denoised ${ }^{87} \mathrm{Sr}$ static spectra of $\mathrm{Sr}\left(\mathrm{NO}_{3}\right)_{2}$ acquired with two-pulse, full Hahn echo sequence after 1 (a), 5 (b) and 15 (c) h of machine time, the first 6 singular values were used; (d) non-denoised spectrum (Fig. 6A-i).

\section{Results and discussion}

Fig. 3A shows denoised ${ }^{29} \mathrm{Si}$ MAS spectra of a layered silicate Magadiite [29] for the number $N_{\mathrm{SVD}}$ of singular values varying from 1 to 5 . The spectrum is recovered with $N_{\mathrm{SVD}} \geq 4$, the latter being the number of ${ }^{29} \mathrm{Si}$ peaks in the spectrum. It consists of a $\mathrm{Q}^{3}$ species peak located at $-99.2 \mathrm{ppm}$ and three $\mathrm{Q}^{4}$ species peaks at $-109.5,-111.1$ and $-113.7 \mathrm{ppm}$. Underestimating the number $N_{\text {SVD }}$ of singular values distort the spectrum (Fig. 3A-a and b) but 
overestimating this number makes spectrum denoising less effective (Fig. 3A-e).

Fig. 3B compares line broadening (LB) denoising with SVD denoising. LB denoised spectrum (Fig. 3B-d) whose noise is comparable to that of SVD denoised spectrum (Fig. 3B-a) has broader line widths, resulting a loss of spectrum resolution. Fig. 3B-a denoised with $N_{\mathrm{SVD}}=4$ shows that SVD denoising neither broaden the line widths nor improve the spectral resolution. Knowing the number of lines in the spectrum helps us to choose the number $N_{\mathrm{SVD}}$ of singular values in the denoising procedure.
Fig. 4A shows TPPM-15 high-power proton decoupled ${ }^{29} \mathrm{Si}$ MAS spectra of hybrid materials for increasing NS varying from 40 to 240 in steps of 40. Fig. 4B shows SVD denoised spectra of that acquired with $60 \mathrm{~h}$ of machine time or NS=1200 for increasing number of singular values $\left(N_{\mathrm{SVD}}\right)$ varying from 1 to 6 in steps of 1 , Fig. 4B-g being the non-SVD denoised spectrum. The spectrum is recovered with $N_{\mathrm{SVD}} \geq 5$, the latter being the number of silicon species in the spectrum. It consists of lines of $\mathrm{T}^{2}$ and $\mathrm{T}^{3}$ species located at -72.5 and $-80.8 \mathrm{ppm}$ and of $\mathrm{Q}^{2}, \mathrm{Q}^{3}$ and $\mathrm{Q}^{4}$ species located at $-93.5,-102.7$ and $-111.9 \mathrm{ppm}$, respectively. $\mathrm{A} \mathrm{Q}^{z}$
A

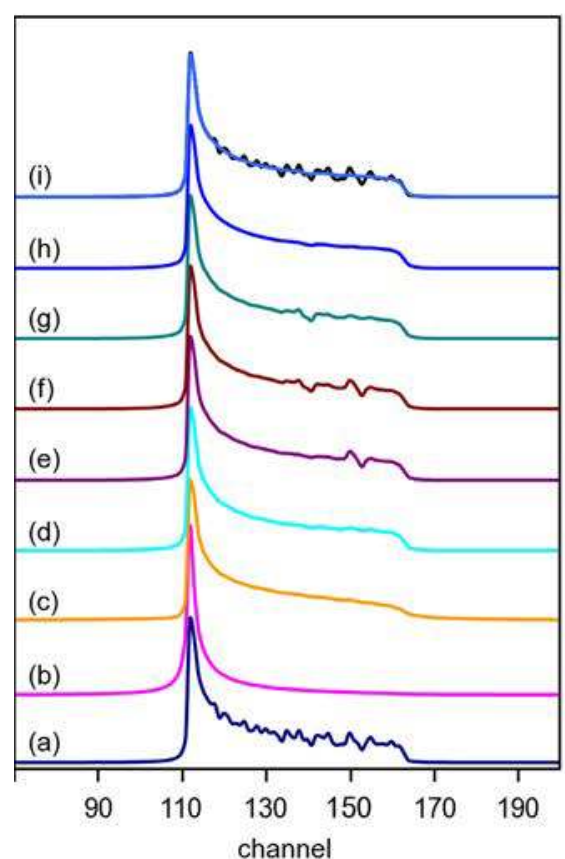

B

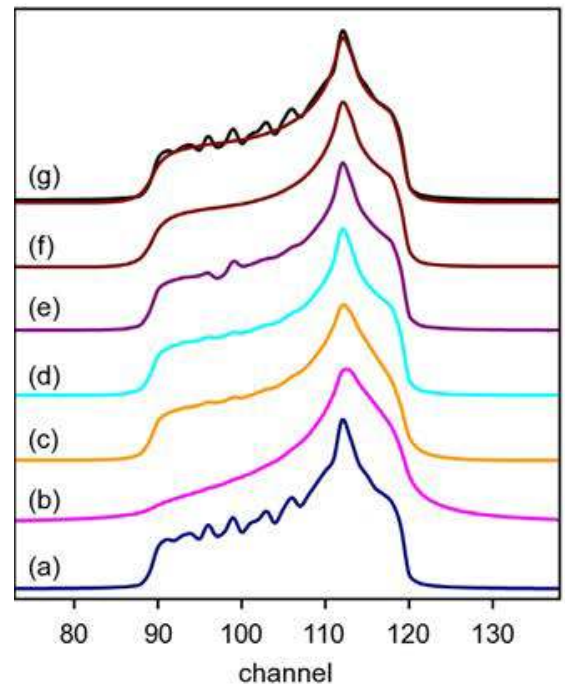

C

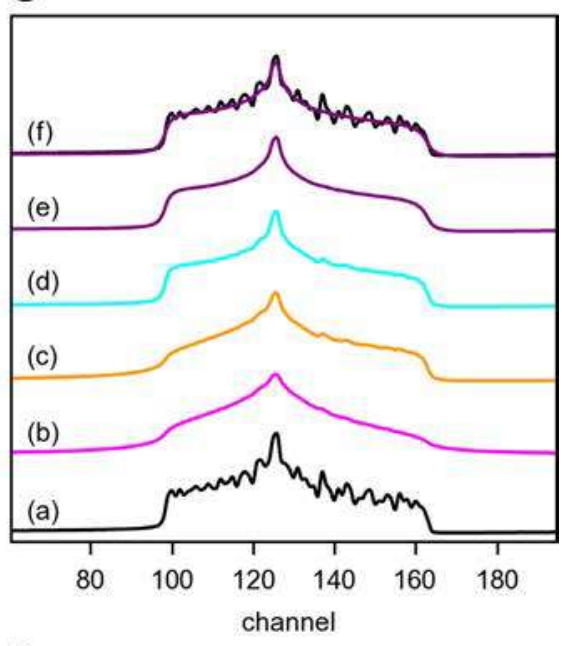

D

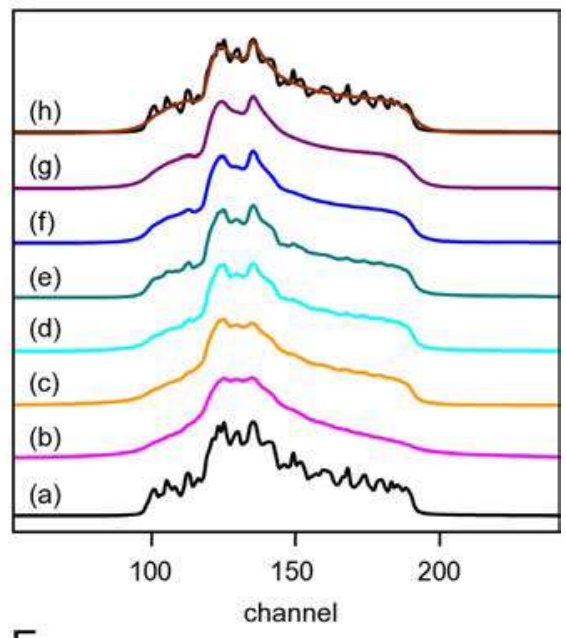

$E$

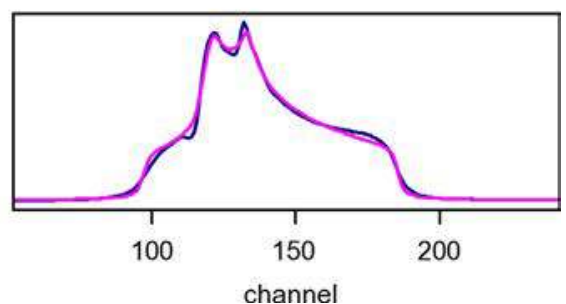

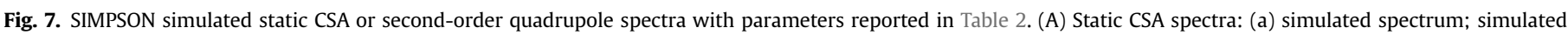

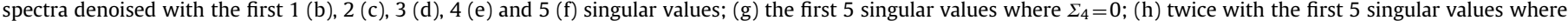

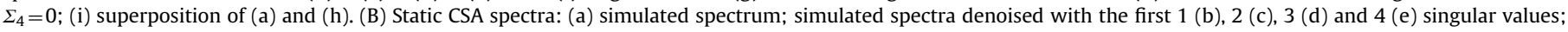

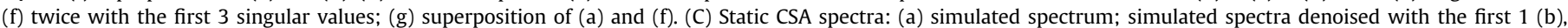

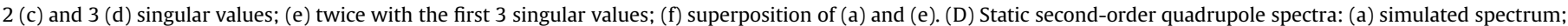

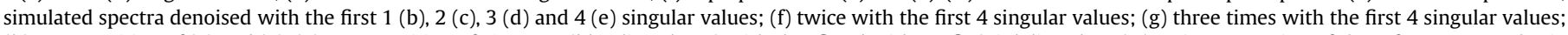

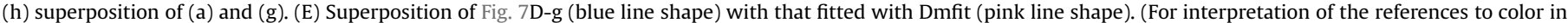
this figure legend, the reader is referred to the web version of this article.) 
Table 2

SIMPSON simulation parameters for spectra in Fig. 7.

\begin{tabular}{|c|c|c|c|c|c|c|c|c|}
\hline \multirow[t]{2}{*}{ Figure } & \multicolumn{6}{|c|}{ Chemical shift anisotropy ${ }^{a}$} & \multicolumn{2}{|c|}{$\begin{array}{l}\text { 2nd-order } \\
\text { quadrupole } \\
\text { interaction }^{\mathrm{b}}\end{array}$} \\
\hline & $\begin{array}{l}\delta_{\text {iso }} \\
(\mathrm{ppm})\end{array}$ & $\begin{array}{l}\delta_{\text {aniso }} \\
(\mathrm{ppm})\end{array}$ & $\eta_{\mathrm{CS}}$ & $\begin{array}{l}\alpha \\
\text { (deg) }\end{array}$ & $\begin{array}{l}\beta \\
\text { (deg) }\end{array}$ & $\begin{array}{l}\gamma \\
\text { (deg) }\end{array}$ & $\begin{array}{l}e^{2} q Q / h \\
(\mathrm{MHz})\end{array}$ & $\eta_{\mathrm{Q}}$ \\
\hline A & 0 & -15.4 & 0 & -5 & -60 & -65 & 0 & 0 \\
\hline B & 10 & 8 & 0.4 & -5 & -60 & -65 & 0 & 0 \\
\hline $\mathrm{C}$ & 0 & -15.4 & 0.8 & -5 & -60 & -65 & 0 & 0 \\
\hline $\mathrm{D}$ & 0 & 0 & 0.8 & -5 & -60 & -65 & 1.15 & 0.8 \\
\hline
\end{tabular}

${ }^{\text {a }}$ Crystal_file zcw986 and number of points $\mathrm{np}=256$ are used.

b The nucleus is ${ }^{43} \mathrm{Ca}, I=7 / 2$, whose Larmor frequency is $26.96 \mathrm{MHz}$.

species signifies a silicon atom bonded to $z$ other silicon atoms via bridging oxygen and $4-z$ non-silicon groups $\mathrm{X}$ via "non-bridging" oxygen, that is, $(\mathrm{XO})_{4-z} \mathrm{Si}(\mathrm{OSi})_{z} \cdot \mathrm{A} \mathrm{T}^{z}$ species signifies a silicon atom bonded to $z$ other silicon atoms via bridging oxygen, $3-z$ nonsilicon groups $\mathrm{R}$ via "non-bridging" oxygen and a non-silicon group $\mathrm{R}^{\prime}$, that is, $(\mathrm{RO})_{3-z} \mathbf{S i}_{\mathrm{R}^{\prime}}^{(\mathrm{OSi})_{z}}$. Fig. $4 \mathrm{C}$ shows the denoised spectra of Fig. 4A where the first 6 singular values are selected, that is, $N_{\mathrm{SVD}}=6$. It is clearly shown that the $\mathrm{S} / \mathrm{N}$ ratio of denoised spectrum acquired for $8 \mathrm{~h}$ machine time (Fig. 4C-d) is as good as that acquired for $60 \mathrm{~h}$ machine time (Fig. 4B-g). These spectra were decomposed as sum of Gaussian line shapes with GSim [30] for determining the relative proportions of the various ${ }^{29} \mathrm{Si}$ species. The ratio of the integrated intensities for $\mathrm{T}$ to $\mathrm{Q}$ species,

$\mathrm{T} / \mathrm{Q}=\Sigma_{i=0}^{3} \mathrm{~T}^{i} / \Sigma_{i=0}^{4} \mathrm{Q}^{i}$,

is reported in Table 1. The $\mathrm{T} / \mathrm{Q}$ ratios from decompositions/ integrations of non-denoised (Fig. 4A) and SVD denoised (Fig. 4C) spectra are similar. It is $\sim 0.25$. As SVD denoised spectra present clean spectral base lines, the initial decomposition of SVD denoised spectra before fitting (that is, base line correction, line positions, line widths, and line intensities), which is performed by us, is less tedious than those of non-denoised spectra. Error bars on integrated line intensities are not provided by GSim.

Fig. 5A shows the superposition of TPPM-15 high-power proton decoupled ${ }^{29} \mathrm{Si}$ MAS QCPMG spikelet spectrum (Fourier transformation of time-domain echo train) of hybrid materials with that of Fig. 4B-g. Fig. 5B and C shows denoised proton decoupled ${ }^{29} \mathrm{Si}$ MAS QCPMG spikelet spectra of hybrid materials for increasing values of $N_{\text {SVD }}$, Fig. 5C-f being the non-denoised spectrum. The spectrum is recovered with $N_{\mathrm{SVD}} \geq 25$, whereas the number of spikelets in the spectrum is 21 in Fig. 5C-f. From a practical point of view, the above examples show that a good guest of $N_{\text {SVD }}$ for SVD denoising is the number of resolved peaks in the spectrum.

Fig. 6A shows denoised static spectra of ${ }^{87} \mathrm{Sr}$ in the reference sample $\mathrm{Sr}\left(\mathrm{NO}_{3}\right)_{2}$ acquired with two-pulse, full Hahn echo sequence and $15 \mathrm{~h}$ of machine time, $N_{\mathrm{SVD}}$ varying from 1 to 8 in steps of 1 , Fig. $6 \mathrm{~A}-\mathrm{i}$ being the non-denoised spectrum. The line shape is recovered with $N_{\mathrm{SVD}} \geq 6$. Fig. 6B shows denoised $\left(N_{\mathrm{SVD}}=6\right){ }^{87} \mathrm{Sr}$ spectra acquired with three machine times: 1 (Fig. 6B-a), 5 (Fig. 6B-b) and $15 \mathrm{~h}$ (Fig. 6B-c), Fig. 6B-d being the non-denoised spectrum acquired with $15 \mathrm{~h}$ of machine time. The denoised line shape of Fig. 6B-b acquired with $5 \mathrm{~h}$ machine time is comparable with that of non-denoised line shape of Fig. 6B-d acquired with $15 \mathrm{~h}$ machine time.

We have applied SVD denoising to experimental NMR timedomain signals. Now, we extend SVD denoising to SIMPSON simulated FIDs associated with asymmetric line shapes in static experiments. Fig. 7 shows 3 series of static chemical shift anisotropic (CSA) spectra
(Fig. 7A-C) and one series of static second-order quadrupole spectra (Fig. 7D). The simulation parameters are reported in Table 2. As the number of singular values for denoising without distorting the line shape cannot be guessed, we check the denoised spectra for increasing $N_{\mathrm{SVD}}$ number starting from 1 . With $N_{\mathrm{SVD}}=3$, the denoised line shapes look like theoretical spectra but present some imperfections: the lines are not smooth. These figures also show that it is possible to apply $N_{\text {SVD }}>3$ and zero some singular values inside the selected range to smooth the line shape. Applying twice the same series of singular values also smooth the line shape. With $N_{\mathrm{SVD}} \sim 5$ and some zeroed singular values inside these 5 values, the line shapes are nearly smooth. We stop the SVD denoising procedure when the smooth line shape can superimpose the non-denoised spectrum. Without SVD denoising, the simulation of similar quality spectra with SIMPSON requires longer computer times for powder averaging. Fig. 7E shows the superposition of the denoised second-order quadrupole line shape (D-g) with its line shape simulated with Dmfit [31]. It is obvious that SVD denoising is not only applicable to MAS spectra of spin $I=1 / 2$ nuclei but also to asymmetric line shapes in static experiments.

\section{Conclusion}

We show that the Cadzow enhancement procedure for denoising time-domain signal is applicable not only to FID, but also to two-pulse, full Hahn echo and QCPMG echo train in NMR of spin $I=1 / 2$ systems such as ${ }^{29} \mathrm{Si}$ and of $\operatorname{spin} I>1 / 2$ systems such as ${ }^{87} \mathrm{Sr}$. It is also applicable to simulated spectrum from powder averaging. It does not distort the line shape contrary to LB denoising which broadens the line width. But it does not improve the spectral resolution. Improving the $\mathrm{S} / \mathrm{N}$ ratio of a spectrum facilitates its component decomposition to determine the $\mathrm{T} / \mathrm{Q}$ ratio in hybrid materials. The number of singular values necessary for denoising is about the number of peaks in MAS spectrum. An asymmetric line shape is recovered with ca. 5 singular values. Thanks to modern GPU, typical SVD duration lasts a few seconds, which allows us to anticipate that denoising 2D spectrum should last a few minutes.

\section{Appendix A. Supporting information}

Supplementary data associated with this article can be found in the online version at http://dx.doi.org/10.1016/j.ssnmr.2014.05.001.

\section{References}

[1] A. Diop, Y. Zaim-Wadghiri, A. Briguet, D. Graveron-Demilly, J. Magn. Reson. B 105 (1994) 17-24.

[2] J.A. Cadzow, IEEE Trans. Acoust. Speech Signal Process. 36 (1988) 49-62.

[3] Wikipedia, Hankel Matrix, Available at: 〈http://en.wikipedia.org/wiki/Hankel_ matrix $\rangle$, (accessed January 2014).

[4] Y.Y. Lin, L.P. Hwang, J. Magn. Reson. A 103 (1993) 109-114.

[5] G. Zhu, W.Y. Choy, G. Song, B.C. Sanctuary, J. Magn. Reson. 132 (1998) 176-178.

[6] D.E. Brown, T.W. Campbell, J. Magn. Reson. 89 (1990) 255-264.

[7] G. Zhu, D. Smith, Y. Hua, J. Magn. Reson. 124 (1997) 286-289.

[8] D. Kim, D.-G. Kim, Y. Lee, H. Won, Bull. Korean Chem. Soc. 24 (2003) 971-974.

[9] C. Brissac, T.E. Malliavin, M.A. Delsuc, J. Biomol. NMR 6 (1995) 361-365.

[10] S.D. Kunikeev, H.S. Taylor, J.-J. Pan, A. Kershaw, C.E. McKenna, J. Organomet Chem. 690 (2005) 2644-2650.

[11] S.D. Kunikeev, H.S. Taylor, T. Schroer, R. Haiges, C.J. Bigler Jones, K.O. Christe, Inorg. Chem. 45 (2006) 437-442.

[12] O. Nikel, D. Laurencin, C. Bonhomme, G.E. Sroga, S. Besdo, A. Lorenz, D. Vashishth, J. Phys. Chem. C 116 (2012) 6320-6331.

[13] J.E. Stone, D.J. Hardy, I.S. Ufimtsev, K. Schulten, J. Mol. Gr. Model. 29 (2010) $116-125$.

[14] L.A. Baumes, F. Kruger, S. Jimenez, P. Collet, A. Corma, Phys. Chem. Chem. Phys. 13 (2011) 4674-4678.

[15] D.N. LeBard, B.G. Levine, P. Mertmann, S.A. Barr, A. Jusufi, S. Sanders, M.L. Klein, A.Z. Panagiotopoulos, Soft Matter 8 (2012) 2385-2397.

[16] D. Wang, W.F. van Gunsterenb, Z. Chai, Chem. Soc. Rev. 41 (2012) 5836-5865.

[17] D.J. Huggins, Phys. Chem. Chem. Phys. 14 (2012) 15106-15117. 
[18] P.P. Man, 2012 Java Application for FID Denoising with SVD, Available at: 〈http://www.pascal-man.com/navigation/faq-java-browser/SVD-Java-applica tion2012.shtml $\rangle$, (accessed January 2014).

[19] P.P. Man, Graphic Processing Unit (GPU), 2012 SVD Java 6 Application for FID Denoising, Available at: 〈http://www.pascal-man.com/navigation/faq-java-b rowser/SVD-Java-application-GPU.shtml〉, (accessed January 2014).

[20] C. Bonhomme, C. Gervais, N. Folliet, F. Pourpoint, C.C. Diogo, J. Lao, E. Jallot, J. Lacroix, J.-M. Nedelec, D. Iuga, J.V. Hanna, M.E. Smith, Y. Xiang, J. Du, D. Laurencin, J. Am. Chem. Soc. 134 (2012) 12611-12628.

[21] F.H. Larsen, J. Skibsted, H.J. Jakobsen, N.C. Nielsen, J. Am. Chem. Soc. 122 (2000) 7080-7086.

[22] G.M. Bowers, A.S. Lipton, K.T. Mueller, Solid State Nucl. Magn. Reson. 29 (2006) 95-103.

[23] M. Bak, J.T. Rasmussen, N.C. Nielsen, J. Magn. Reson. 147 (2000) 296-330.

[24] V. Olshevsky, M. Stewart, Numer. Linear Algebr. Appl. 189 (2001) 401-434.
[25] X. Zhao, B. Ye, Mech. Syst. Signal Process. 23 (2009) 1062-1075.

[26] A. Diop, A. Briguet, D. Graveron-Demilly, Magn. Reson. Med. 27 (1992) 318-328.

[27] Wikipedia, Toeplitz Matrix, Available at: 〈http://en.wikipedia.org/wiki/Toe plitz_matrix $\rangle$, (accessed January 2014).

[28] P.P. Man, Quadrupolar interactions, in: R.K. Harris, R.E. Wasylishen (Eds.) Encyclopedia of Magnetic Resonance, J. Wiley, Chichester, 2011 (Available at: $\langle$ http://www.pascal-man.com/book/emr2011.pdf >).

[29] E. Burzo, Phyllosilicates, Springer-Verlag, Berlin, 2009 (Available at: $\langle$ http:/ books.google.fr/books?id=0991cBcZb-MC >).

[30] V.E. Zorin, GSim - visualisation and processing tool for NMR experiments and simulations, Available at: 〈http://sourceforge.net/projects/gsim/〉, (accessed January 2014).

[31] D. Massiot, F. Fayon, M. Capron, I. King, S. Le Calvé, B. Alonso, J.-O. Durand, B. Bujoli, Z. Gan, G. Hoatson, Magn. Reson. Chem. 40 (2002) 70-76. 